\title{
Site-specific methylation of placental HSD11B2 gene promoter is related to intrauterine growth restriction
}

\begin{abstract}
Yan Zhao ${ }^{1,4}$, Xia Gong ${ }^{2,4}$, Li Chen ${ }^{1}$, Luxi Li $^{1}$, Yuan Liang ${ }^{3}$, ShangQin Chen ${ }^{3}$ and Yunhui Zhang ${ }^{\star, 1}$
Intrauterine growth restriction (IUGR) is associated with detrimental effects on neurodevelopmental progress in childhood and higher risk of degenerative diseases in adulthood. Placental $11 \beta$-hydroxysteroid dehydrogenase (HSD11B2) is a key gene involved in glucocorticoid metabolism, which in turn seems to be related to fetal growth impairment. As reduction of placental HSD11B2 gene expression has been associated with reduced human fetal growth, and methylation of HSD11B2 gene promoter has been shown to have an important role in HSD11B2 gene repression, we seek to investigate the relationship between IUGR and HSD11B2 gene promoter methylation in human placentas. We found that methylation levels of all studied $\mathrm{CpG}$ sites were significantly higher in IUGR newborns than those in controls. Further, methylation levels of the first and the third CpG sites were inversely associated with measures of fetal growth (birth weight and ponderal index). In addition, consistent with the above negative correlation, methylation levels of the first and the third CpG sites were inversely associated with HSD11B2 gene expression. These results together show a link between the site-specific methylation of placental HSD11B2 promoter and the development of IUGR.
\end{abstract}

European Journal of Human Genetics (2014) 22, 734-740; doi:10.1038/ejhg.2013.226; published online 16 October 2013

Keywords: DNA methylation; IUGR; HSD11B2; placenta; birth weight

\section{INTRODUCTION}

A pathological restriction of fetal growth due to adverse genetic or environmental influences is called intrauterine growth restriction (IUGR). Birth weight and/or birth length of infants with IUGR are below the 10th percentile for gestational age (GA). ${ }^{1}$ IUGR is the most important cause of perinatal mortality and morbidity, affecting $\sim 7-15 \%$ of pregnancies. ${ }^{2-4}$ The sequelae of IUGR include still birth, detrimental effects on neurodevelopmental progress in childhood, and higher risk of degenerative diseases (for example, vascular disease, diabetes, and hypertension) in adulthood. ${ }^{5,6}$

Evidences from animal and human studies have shown that glucocorticoid excess in utero impaired fetal growth. ${ }^{7,8}$ It is also noteworthy that IUGR newborns appear to have elevated cortisol levels. ${ }^{9-11} \mathrm{~A}$ key factor in determining glucocorticoid hormone action is the 'prereceptor' role played by two distinct isozymes of $11 \beta$-hydroxysteroid dehydrogenase $(11 \beta$-HSD1 and $11 \beta$-HSD2 coded by $H S D 11 B 1$ and $H S D 11 B 2$, respectively), which interconvert hormonally active cortisol to inactive cortisone. $11 \beta$-HSD1 is expressed in the maternal decidua but low or absent in human fetal tissues including trophoblast, whereas $11 \beta$-HSD2 is widely distributed in human fetal tissues, including the placental trophoblast where it is expressed in particularly high abundance. ${ }^{12-15}$ In placental tissues, $11 \beta$-HSD2 converts maternal cortisol to its inactive metabolite, cortisone, regulating the amount of maternal cortisol to the fetus. ${ }^{16,17}$ Therefore, it is postulated that placental $11 \beta$-HSD2 enzyme serves as a functional barrier to protect the fetus from relatively high levels of maternal glucocorticoids.
Reductions in placental 11 $\beta$-HSD2 expression have been associated with reduced human fetal growth. Previous human studies have demonstrated that there was a significant reduction in $11 \beta$-HSD2 enzyme activity in placentas from deliveries complicated by IUGR, and further studies demonstrated that there were also reductions in placental HSD11B2 gene expression. ${ }^{17-21}$

How to explain the reduced placental HSD11B2 gene expression in IUGR newborns? Although mutations in HSD11B2 gene were detected in all patients with the syndrome of apparent mineralocorticoid excess, which was due to $11 \beta$-HSD2 deficiency, ${ }^{22}$ no mutation was found in HSD11B2 gene from DNA extracted from IUGR placentas. ${ }^{19}$ In addition, imprinting analysis revealed that placental HSD11B2 gene was not imprinted. ${ }^{19}$ To date, the mechanism leading to a reduction of placental HSD11B2 gene expression in IUGR newborns remains speculative.

Recently, evidences from animal and human studies suggested a role for DNA methylation in HSD11B2 gene regulation. Analysis of human HSD11B2 gene showed two CpG islands located in the promoter and exon 1 (nucleotides -633 to -97 and -77 to +460 ) and two CpG islands in exon 5 and the downstream region (nucleotides +5569 to +5721 and +7357 to +7515$){ }^{23,24}$ One cross-sectional study conducted in Rhode island associated placental HSD11B2 methylation with adverse birth outcomes (for example, lower birth weight, smaller ponderal index and IUGR), demonstrating that methylation levels of placental HSD11B2 gene promoter were inversely associated with placental HSD11B2 expression. ${ }^{25}$ The association between placental HSD11B2 methylation and IUGR needs more studies to confirm.

${ }^{1}$ Key Laboratory of Public Health Safety, Ministry of Education, School of Public Health, Fudan University, Shanghai, China; ${ }^{2}$ Department of Ultrasound, Shanghai Huashan Hospital, Fudan University, Shanghai, China; ${ }^{3}$ Department of Neonatology, The 2nd Affiliated Hospital, Wenzhou Medical College, Wenzhou, China

${ }^{4}$ These authors contributed equally to this work.

*Correspondence: Professor Yunhui Zhang, Key Laboratory of Public Health Safety, Ministry of Education, School of Public Health, Fudan University, P.O. Box 249, 138 Yixueyuan Road, Shanghai 200032, China. E-mail: yhzhang@shmu.edu.cn

Received 3 March 2013; revised 6 August 2013; accepted 16 August 2013; published online 16 October 2013 
In this case-control study, we investigated whether there were any alterations in DNA methylation of placental HSD11B2 gene promoter in deliveries complicated by IUGR, and further explored whether these alterations were associated with the development of IUGR in an Asian population.

\section{METHODS}

\section{Study population}

The participants were recruited from the Second Affiliated Hospital of Wenzhou Medical College between December 2011 and March 2012. IUGR cases were diagnosed prospective and rigorous, having at least three of the four ultrasound-derived criteria: (1) an abdominal circumference, less than or equal to the third centile for GA; (2) abnormal umbilical artery Doppler waveforms; (3) oligohydramnios; and (4) abnormal fetal growth velocity ( $\Delta$ abdominal circumference $<1.5 \mathrm{SD}$ over 14 days). No fetuses had congenital anomalies or aneuploidy. During the study period, a total of 500 infants were born, and 22 $(4.4 \%)$ of them were IUGR. All IUGR newborns were included in this study as cases and an equal number of healthy newborns were included as controls. A total of 44 subjects, 22 term IUGR newborns, and 22 control term newborns, and their mothers were enrolled in our study. All subjects were residents of Wenzhou and signed written informed consents approved by Fudan University's Institutional Review Board. The mothers answered a detailed questionnaire concerning maternal age, maternal weight, and height before pregnancy, smoking, drinking, dietary habits, and so on, after delivery within 2 days. The demographic characteristics of newborns, including birth weight, birth length, and GA (calculated by subtracting the date of the last menstrual period from the date of delivery) were obtained from hospital records.

Placenta samples were collected immediately after delivery. For each subject, eight biopsies of apparently normal tissue were collected (two from each of the four quadrants). All samples were taken from the maternal side of the placenta, $2 \mathrm{~cm}$ from the umbilical cord insertion site, free of maternal decidua. After washing three times in sterile phosphate-buffered saline, samples were immediately frozen in liquid nitrogen and stored at $-80{ }^{\circ} \mathrm{C}$ until analysis.

\section{DNA extraction and bisulfite modification}

A pooled sample $(120 \mathrm{mg}$ ) for each placenta that comprised four biopsies (two from the upper left-hand quadrant and two from the lower right-hand quadrant) was used for DNA extraction. Genomic DNA was extracted using the QIAmp DNA Mini Kit (Qiagen, Hilden, Germany) according to the manufacturer's instructions. Purified DNA was quantified using a ND1000 spectrophotometer (Nanodrop, Wilmington, DE, USA) and about $500 \mathrm{ng}$ DNA was bisulfite modified using the EZ Methylation Gold-Kit (Zymo Research, Orange, CA, USA). The converted DNA was eluted in $10 \mu \mathrm{l}$ of $0.1 \times \mathrm{TE}$ buffer and stored at $-20{ }^{\circ} \mathrm{C}$ until analysis.

\section{PCR and pyrosequencing assay for HSD11B2 methylation}

The studied region located in the promoter of placental HSD11B2 (bases -692 to -595 , relative to the start of transcription). The size of this region is $97 \mathrm{bp}$, which contains four CpG sites. One PCR assay was designed to amplify this region. The amplified primers targeted $\mathrm{CpG}$-free regions to ensure that the PCR products would proportionally represent the methylation characteristics of the source DNA (Supplementary Figure S1). We used following amplification primers: HSD11B2-F, 5'-AAGTTTTGGAAGGAAAGGGA AAGA-3' ${ }^{\prime}$, and HSD11B2-R, 5'-biotin-ACAAAACCTACCTAAAACAAAAACTA-3'. Hot-start PCR was carried out with HotStar Taq Master Mix Kit (Qiagen) and each PCR mix consisted of the converted DNA, $1.5 \mathrm{~mm} \mathrm{MgCl}_{2}, 200 \mu \mathrm{M}$ dNTPs, $10 \mathrm{pmol}$ forward primer, $10 \mathrm{pmol}$ reverse primer, and $1.25 \mathrm{U}$ HotStar Taq Polymerase. Reaction conditions were $95^{\circ} \mathrm{C}$ for $15 \mathrm{~min}$ and then 40 cycles of $94{ }^{\circ} \mathrm{C}$ for $30 \mathrm{~s}, 58^{\circ} \mathrm{C}$ for $30 \mathrm{~s}$, and $72^{\circ} \mathrm{C}$ for $1 \mathrm{~min}$, with a final extension of $7 \mathrm{~min}$ at $72^{\circ} \mathrm{C}$. The presence or absence of PCR products and freedom from PCR contamination was established on $1.5 \%$ agarose gels with ethidium bromide staining.

All gel-positive PCR products were sequenced using PyroMark Q96 system (Qiagen) according to the manufacturer's instructions. Sequencing primer (HSD11B2-seq, 5'-GGGGTAGAGATTTTAAGAA-3'), which also targeted
CpG-free regions, was designed to sequence four CpG sites in the HSD11B2 promoter regions (Supplementary Figure S1). The nucleotide dispensation order for the assays was $5^{\prime}$-GTCGATG TCAGTCGTTAGTTCGTA-3'. It was not practical to confirm complete bisulfite conversion at every unmethylated cytosine; nonetheless, we used a non-CpG cytosine residue as built-in control (see arrows in Supplementary Figure S2) to ensure successful bisulfite conversion of unmethylated cytosine. All samples (including 22 cases and 22 controls) were tested in triplicate and there was no missing. The variability between replicates was $<1.5 \%$. Methylation level of each CpG site was expressed as methylated cytosines over the sum of methylated and unmethylated cytosines. Two representative pyrograms of pyrograms obtained from IUGR case and control samples were shown in Supplementary Figure S2. All methylation data were submitted to MethDB (http://www.methdb.de).

\section{Extraction of total RNA, and quantitative RT-PCR}

Total RNA was extracted from pooled samples $(120 \mathrm{mg})$ using the 'Trizol method' (Invitrogen, Carlsbad, CA, USA). Briefly, homogenized placenta samples ( $1 \mathrm{ml}$ TRIzol reagent per $50 \mathrm{mg}$ tissue) were incubated at room temperature for $5 \mathrm{~min}$. Then, $0.2 \mathrm{ml}$ chloroform was added to the homogenate. The mixture was shaken vigorously for $15 \mathrm{~s}$ and centrifuged at $12000 \mathrm{~g}\left(4^{\circ} \mathrm{C}\right)$ for $15 \mathrm{~min}$. The supernatant was removed to a new tube and $0.5 \mathrm{ml}$ isopropanol was added. After standing at room temperature for $10 \mathrm{~min}$, the solution was centrifuged at $12000 \mathrm{~g}\left(4^{\circ} \mathrm{C}\right)$ for $10 \mathrm{~min}$ and the supernatant was removed. The pellet was washed with $1 \mathrm{ml} \mathrm{75 \%}$ ethanol for twice and dissolved in $20 \mu$ l diethylpyrocarbonate-treated water. Purified RNA was quantified using an ND1000 spectrophotometer (Nanodrop). The integrity of the RNA was assessed by the presence of two sharp bands representing $28 \mathrm{~S}$ and $18 \mathrm{~S}$ ribosomal RNA after agarose gel (1\%) electrophoresis followed by staining with ethidium bromide. About $500 \mathrm{ng}$ of total RNA was reverse transcribed using a Takara RT system (Takara Bio, Dalian, China) according to the manufacturer's protocol.

SybrGreen Real-Time PCR was used to determine mRNA abundance of HSD11B2 in placental samples. Primers for HSD11B2 and GAPDH (housekeeping control) were designed by the use of Primer Express software (PerkinElmer Applied Biosystems, Warrington, UK) according to the published sequences (NCBI Accession number, U27317 for HSD11B2 and M33197 for $G A P D H)$. The following sequences for the primers were used: $11 \beta-H S D 2$, forward primer $5^{\prime}$-TCAAGACAGAGTCAGTGAGA AACG-3' and reverse primer 5'-GGAACTGCCCATGCAAGTG-3'; GAPDH, forward primer $5^{\prime}$-ATCAC CATCTTCCAGGAGCGA-3' and reverse primer $5^{\prime}$-CCTTCT CCATGGTGGTG AAGAC- $3^{\prime}$. Real-time PCR was carried out in a $25-\mu$ l volume containing $30-50 \mathrm{ng}$ of reverse transcribed samples, $600 \mathrm{~nm}$ of each primer, and $12.5 \mu \mathrm{l}$ of $2 \times$ SybrGreen master mix (Perkin-Elmer Applied Biosystems). Reaction conditions were as follows: $50^{\circ} \mathrm{C}$ for $2 \mathrm{~min}, 95^{\circ} \mathrm{C}$ for $10 \mathrm{~min}$, and then 40 cycles of $95^{\circ} \mathrm{C}$ for $15 \mathrm{~s}$ and $60^{\circ} \mathrm{C}$ for $1 \mathrm{~min}$. PCR analysis was performed using the ABI Prism7700 Detection System (Perkin-Elmer Applied Biosystems). All reactions were run in triplicate, with GAPDH serving as a referent ${ }^{26}$ and the coefficient of variation value was within $3.0 \%$. Relative quantification of gene expression was performed using the comparative $C_{\mathrm{t}}$ method. The amount of target gene, normalized to GAPDH and relative to a calibrator, was determined by the arithmetic formula $2^{-\Delta \Delta C t}$.

\section{Statistical analysis}

As methylation levels of these four $\mathrm{CpG}$ sites were not homogeneous, the overall mean methylation levels of four $\mathrm{CpG}$ sites were not suitable for assessing the methylation status of HSD11B2 gene promoter. Thus, methylation level (average of three replicates) of each CpG site was utilized in all analyses.

Methylation level was used as continuous variable. Ponderal index at birth, which was calculated as birth weight in kilograms divided by the cube of birth length in meters, was also treated as continuous variable. Normally distributed continuous variables were expressed as mean \pm S.D., and parametric $t$-test and $\chi^{2}$-test were used to compare demographic characteristics in the IUGR mother-newborn pairs and controls. Potential differences in methylation levels of the placental HSD11B2 gene promoter between IUGR cases and controls were evaluated through parametric $t$-tests. 
As methylation extent was normally distributed, associations between birth outcomes and methylation level of each CpG site were assessed using the Pearson correlation analysis. To take into account potential confounding variables, multiple linear regression models were used to model associations between methylation level of each CpG site and fetal growth indexes. Variables considered in this analysis included infant GA (a priori selected variable), gender, maternal age, prepregnancy BMI, maternal smoking before or during pregnancy, and maternal pregnancy weight gain. Stepwise regression was used to determine which variable should be included in the linear regression models. The analyses were considered statistically significant when $P<0.05$. All statistical analyses were conducted using the SPSS 16.0 statistical package (SPSS Inc., Chicago, IL, USA).

\section{RESULTS}

\section{Population characteristics}

Demographic characteristics of IUGR cases and controls were listed and compared, as shown in Table 1. IUGR newborns had lower birth weight, shorter birth length, shorter GA, and smaller ponderal index than controls. Two of the control mothers and five case mothers reported pregnancy complications (including pregnancy-induced hypertension, diabetes, infection, and intrahepatic chobvlestasis syndrome). IUGR newborns had lower maternal education background than controls $(P=0.001)$. Mothers from both IUGR group

Table 1 Selected characteristics of IUGR newborns and controls

\begin{tabular}{|c|c|c|c|}
\hline Characteristics & Cases $(n=22)$ & Controls $(\mathrm{n}=22)$ & P-value ${ }^{a}$ \\
\hline \multicolumn{4}{|l|}{ Sex } \\
\hline Male & 9 & 9 & 1.000 \\
\hline Female & 13 & 13 & \\
\hline Birth weight $(\mathrm{kg})^{\mathrm{b}}$ & $2.318 \pm 0.318$ & $3.195 \pm 0.408$ & $0.000 * *$ \\
\hline Birth length $(\mathrm{cm})^{\mathrm{b}}$ & $47.500 \pm 2.133$ & $50.640 \pm 1.093$ & $0.000 * *$ \\
\hline Ponderal index $\left(\mathrm{g} / \mathrm{cm}^{3} \times 100\right)^{\mathrm{b}}$ & $2.175 \pm 0.375$ & $2.459 \pm 0.294$ & $0.008 * *$ \\
\hline Gestational age $(\text { week })^{\mathrm{b}}$ & $37.468 \pm 2.587$ & $39.214 \pm 0.642$ & $0.004 * *$ \\
\hline Maternal age $(y e a r)^{b}$ & $27.82 \pm 4.02$ & $26.50 \pm 2.69$ & 0.208 \\
\hline Paternal age $\left(\right.$ year) ${ }^{\mathrm{b}}$ & $27.86 \pm 3.23$ & $28.45 \pm 2.77$ & 0.518 \\
\hline Pre-pregnant $\mathrm{BMI}{ }^{\mathrm{b}}$ & $19.05 \pm 2.21$ & $19.08 \pm 1.43$ & 0.957 \\
\hline \multicolumn{4}{|l|}{ Smoking during pregnancy } \\
\hline Yes & 0 & 0 & 1.000 \\
\hline No & 22 & 22 & \\
\hline \multicolumn{4}{|l|}{ Drinking during pregnancy } \\
\hline Yes & 0 & 0 & 1.000 \\
\hline No & 22 & 22 & \\
\hline \multicolumn{4}{|l|}{ Education } \\
\hline Junior middle school & 10 & 1 & $0.001^{* *}$ \\
\hline High school & 5 & 2 & \\
\hline College & 7 & 19 & \\
\hline \multicolumn{4}{|l|}{ Monthly income per family } \\
\hline$<5000 \mathrm{RMB}$ & 11 & 6 & 0.122 \\
\hline$\geq 5000 \mathrm{RMB}$ & 11 & 16 & \\
\hline \multicolumn{4}{|l|}{ Pregnancy complications ${ }^{\complement}$} \\
\hline Yes & 5 & 2 & 0.410 \\
\hline No & 17 & 20 & \\
\hline
\end{tabular}

and control group had no habit of cigarette smoking or alcohol drinking during pregnancy. In addition, there were no significant differences between the two groups with respect to infant sex, maternal age, paternal age, pre-pregnant BMI, and monthly income.

\section{Difference in DNA methylation level between IUGR cases and controls}

Mean methylation levels of four CpG sites were: 9.36, 21.36, 10.64, and $19.50 \%$ in IUGR cases and $7.05,19.00,9.00$, and $17.32 \%$ in controls. Correlations between DNA methylation levels in each CpG site are shown in Supplementary Table S1. Results showed that methylation levels in each CpG site were highly correlated. Parametric $t$-test was used to compare the difference in methylation levels between IUGR cases and controls. As shown in Figure 1, methylation levels of all studied CpG sites were significantly higher in IUGR cases than those in controls (methylation difference: $2.31,2.36,1.64$, and $2.18 \% ; P=0.020,0.021,0.027$, and 0.029 , respectively).

\section{Association between HSD11B2 methylation levels and birth outcomes}

The Pearson correlation analysis was used to evaluate the associations between methylation level of each CpG site and birth weight SD score (SDS) $\quad(\mathrm{SDS}=($ actual measurement - expected mean for GA and sex)/SD around mean) (Figure 2). Results showed that methylation levels of the first and the third CpG sites had significant inverse association with birth weight SDS $(r 1=-0.454, \quad P=0.002$; $r 3=-0.298, P=0.049)$. After controlling for GA and birth length, methylation levels of the first and the third CpG sites were inversely associated with birth weight $(\beta 1=-0.062, P=0.009 ; \beta 3=-0.048$, $P=0.043$; Table 2). Per interquartile range increase in DNA methylation levels of the first and the third CpG sites associated with 186 and $144 \mathrm{~g}$ reduction in birth weight, respectively.

A significant negative correlation $(r=-0.401 ; P=0.008)$ was found between methylation level of the first $\mathrm{CpG}$ site and birth length (data not shown). However, this significance disappeared ( $\beta=0.040 ; P=0.726)$ when controlling for GA and birth weight (Table 2).

Figure 3 showed that elevated methylation levels of the first and the third CpG sites were associated with smaller ponderal index

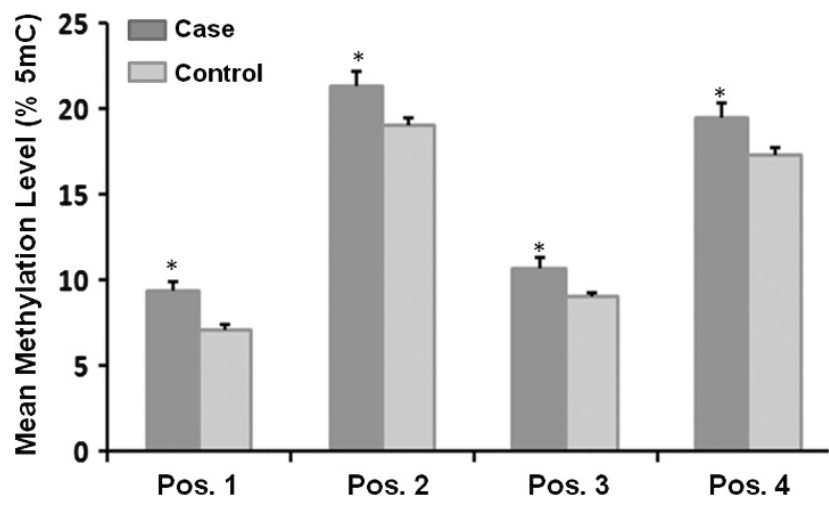

Figure 1 Difference in methylation levels between IUGR cases $(N=22)$ and controls $(N=22)$. Methylation levels of all studied $\mathrm{CpG}$ sites were evaluated by pyrosequencing. Data shown are mean \pm SEM. Mean methylation levels of four CpG sites were: 9.36, 21.36, 10.64, 19.50\% in IUGR cases and $7.05,19.00,9.00,17.32 \%$ in controls. A significant difference compared with controls was shown at ${ }^{*} P<0.05$. 

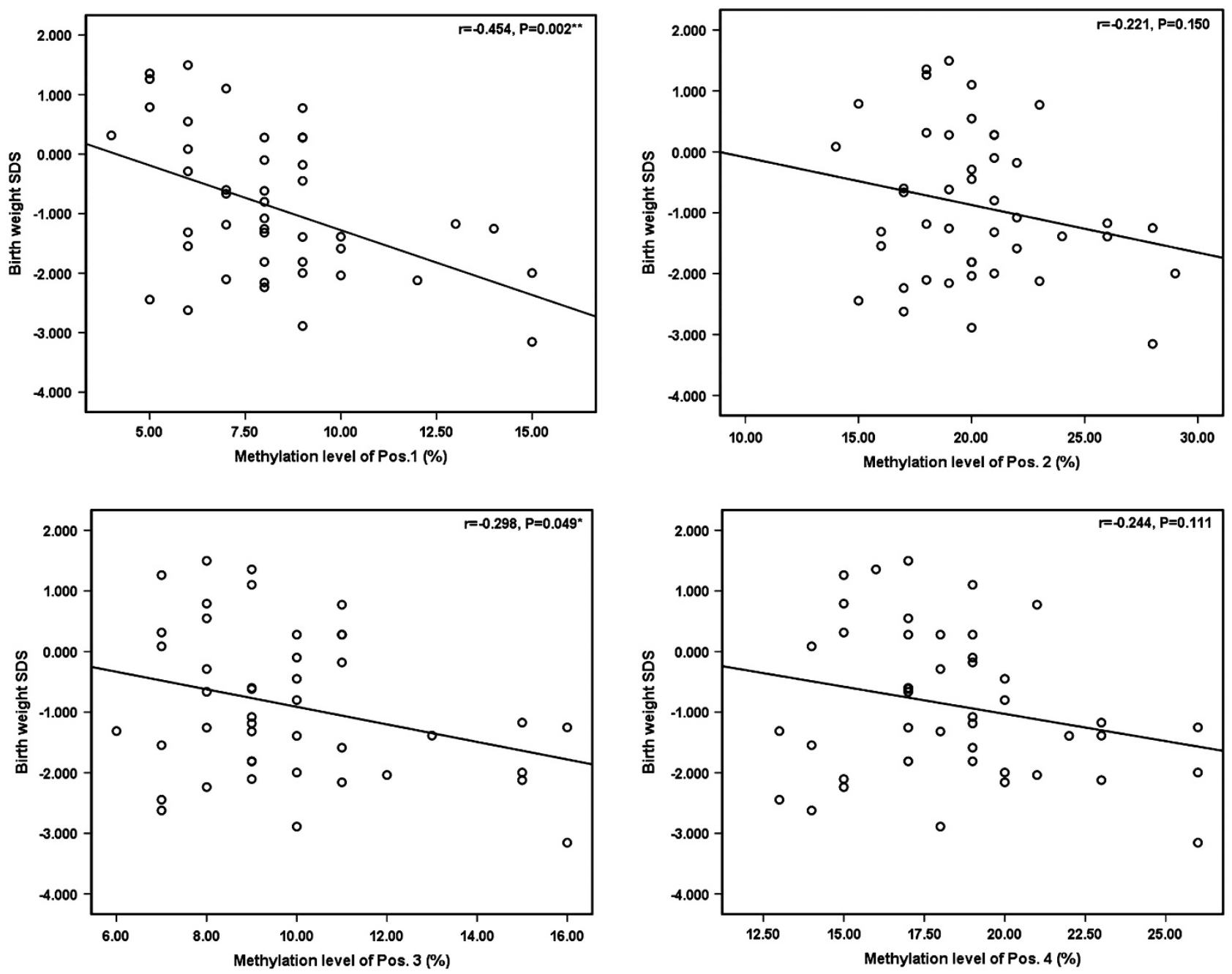

Figure 2 Plots of the correlations between HSD11B2 methylation levels and newborn birth weight SDS. Scatterplots depict the correlation of HSD11B2 methylation levels ( $x$ axis) and newborn birth weight SDS, with the Pearson correlation coefficient $(r)$ and associated $P$-value provided. Methylation levels of the first and the third $\mathrm{CpG}$ sites were significantly inversely associated with newborn birth weight SDS.

Table 2 Association between methylation level of each CpG site and fetal growth

\begin{tabular}{|c|c|c|c|c|c|c|c|c|}
\hline Newborn characteristic & \multicolumn{2}{|c|}{ Pos.1 } & \multicolumn{2}{|c|}{ Pos. 2} & \multicolumn{2}{|c|}{ Pos.3 } & \multicolumn{2}{|c|}{ Pos. 4} \\
\hline Birth weight (per kg)a & -6.17 & $0.009^{* *}$ & -1.71 & 0.343 & -4.76 & $0.043^{*}$ & -2.68 & 0.146 \\
\hline Newborn ponderal index $\left(\text { per } \mathrm{g} / \mathrm{cm}^{3} \times 100\right)^{c}$ & -4.90 & $0.017^{*}$ & -1.87 & 0.249 & -4.76 & $0.022 *$ & -2.60 & 0.113 \\
\hline Gestational age $\left(\right.$ per week) ${ }^{d}$ & -14.66 & 0.140 & -14.36 & 0.057 & -13.89 & 0.176 & -13.53 & 0.087 \\
\hline
\end{tabular}

Methylation level of each CpG site located in HSD11B2 promoter was modeled as the independent variable associated with newborn characteristic as the dependent variable.

aModels controlled for gestational age and birth length.

Models controlled for gestational age and birth weight.

cModels controlled for gestational age and maternal age.

${ }^{\mathrm{d}}$ Models controlled for gender and maternal age.

${ }^{*} P<0.05,{ }^{* *} P<0.01$.

$(r 1=-0.382, P=0.011 ; r 3=-0.346, P=0.021)$. After controlling for GA and maternal age, these associations remained significant $(\beta 1=-0.049, \quad P=0.017 ; \beta 3=-0.048, P=0.022$; Table 2$)$. Per interquartile increase in DNA methylation levels of the first and the third CpG sites associated with 0.147 and 0.144 reduction in pondernal index, respectively.
In our study, although IUGR newborns seemed to have shorter GA than control newborns, we did not find any association between methylation level of each CpG site and GA (Table 2).

Taken together, these results demonstrated that measures of fetal growth were associated with methylation level of single CpG site located in HSD11B2 gene promoter in the placenta. 

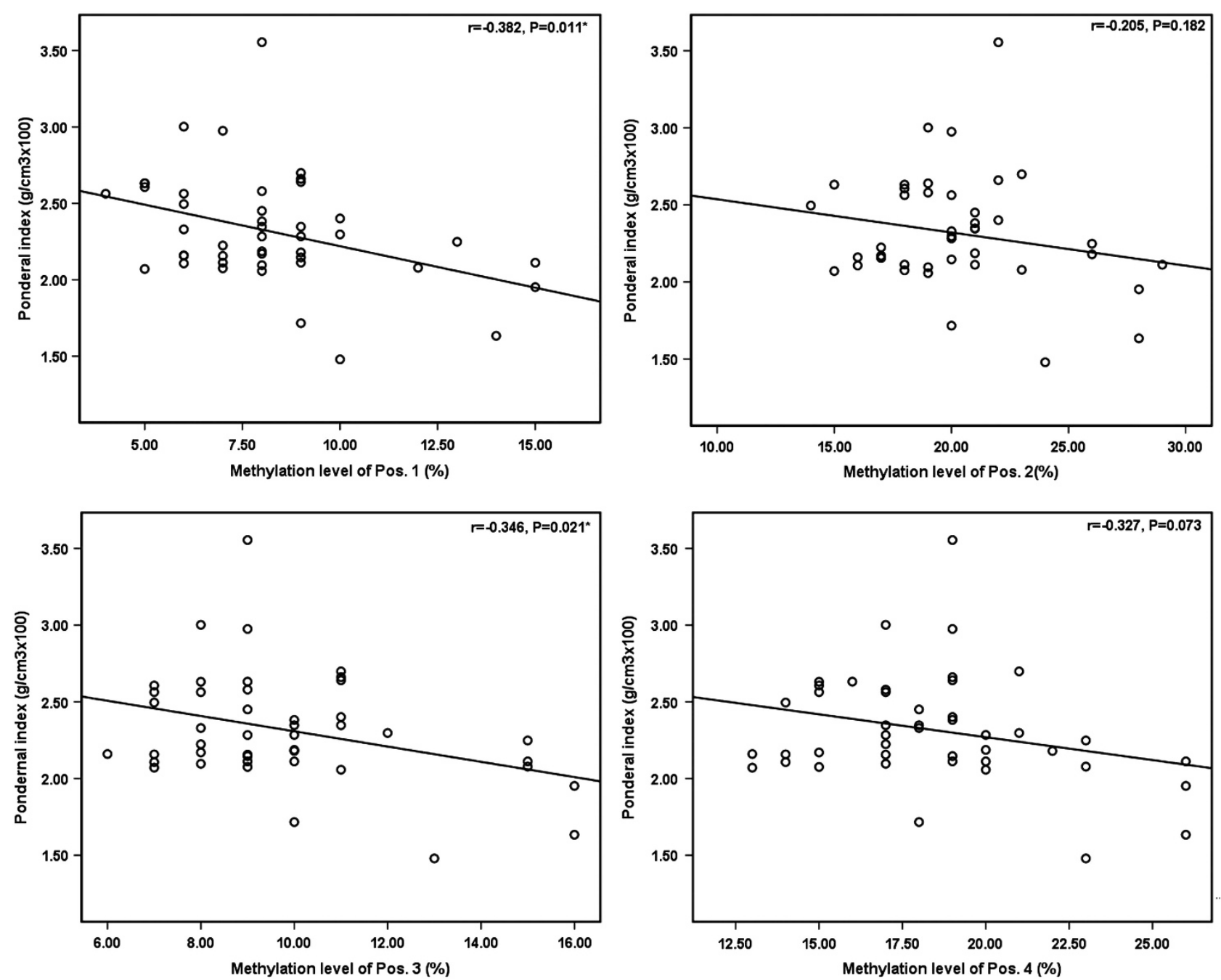

Figure 3 Plots of the correlations between HSD11B2 methylation levels and newborn ponderal index. Scatterplots depict the correlation of HSD11B2 methylation level ( $x$ axis) and newborn ponderal index in $\mathrm{g} / \mathrm{cm}^{3} \times 100$, with the Pearson correlation coefficient $(r)$ and associated $P$-value provided. Methylation levels of the first and the third CpG site were significantly inversely associated with ponderal index at birth.

\section{Association between promoter methylation level and HSD11B2 gene expression}

In order to demonstrate the functional role of promoter methylation on HSD11B2 gene expression, we analyzed HSD11B2 gene expression. The relative abundance of HSD11B2 mRNA compared with GAPDH mRNA was assessed by quantitative real-time RT-PCR. Results showed that HSD11B2 mRNA levels were significantly reduced in placentas from deliveries complicated by IUGR $(P=0.003$; Figure 4$)$. When considered IUGR case and control subjects as a whole, a moderate, statistically significant negative correlations $(r 1=-0.329$, $P=0.029 ; r 3=-0.288, P=0.045)$ were observed between methylation levels of the first and the third $\mathrm{CpG}$ sites and normalized HSD11B2 mRNA expression (Table 3).

\section{DISCUSSION}

Alterations to the placental expression of genes involved in metabolic and endocrine, including those involved in cortisol metabolism, during intrauterine period have been shown to affect the proper growth of the fetus. ${ }^{27}$ As reduction of placental HSD11B2 expression is known to be associated with the development of IUGR ${ }^{18-20}$ and methylation of HSD11B2 gene promoter has been shown to have an important role in $H S D 11 B 2$ gene repression, ${ }^{23}$ we sought to investigate whether methylation of placental HSD11B2 gene promoter was associated with the development of IUGR.

Results of our study showed that methylation levels of all studied CpG sites located in placental HSD11B2 gene promoter regions were slightly but significantly higher in IUGR newborns than those in controls. Although the differences were small, they were higher than the reproducibility (variability between replicates was $1.5 \%$ ) of our pyrosequencing assay. Our results were consistent with a large crosssectional study $(N=186)$, which showed that the difference in methylation levels of placental HSD11B2 gene promoter between IUGR cases and controls was within $2.0 \%$. The smaller average differences might be related to the inherent stochastic nature of epigenetic processes ${ }^{28}$ and the small sample size of our study.

Specially, we found that methylation levels of the first and the third CpG sites were inversely associated with birth weight and ponderal index, which were also consistent with the above cross-sectional study. ${ }^{25}$ In their study, Marsit et $a l^{25}$ found that overall mean methylation levels of four studied CpG sites were inversely associated with birth weight and pondernal index. They also showed that elevated methylation levels of placental HSD11B2 


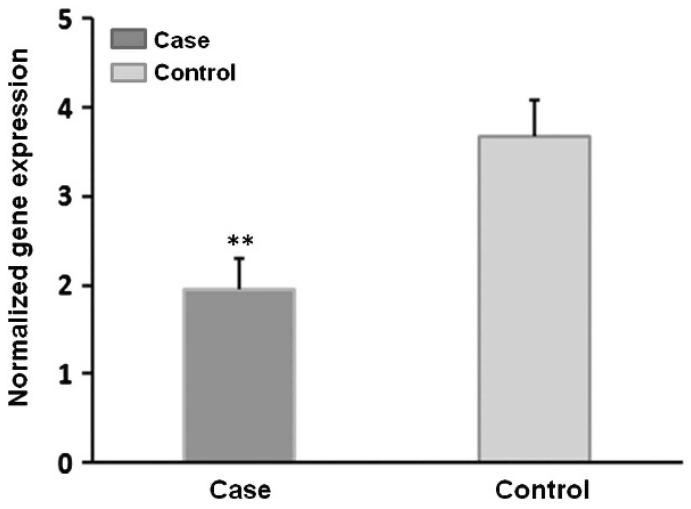

Figure 4 Difference in HSD11B2 expression between IUGR cases $(N=22)$ and controls $(N=22)$. HSD11B2 expression was evaluated by SybrGreen Real-Time PCR. Data shown are mean \pm SEM. Mean HSD11B2 mRNA levels of IUGR cases and controls were 1.942 and 3.667, respectively. A significant difference compared with controls was shown at ${ }^{*} P<0.01$.

Table 3 Correlations between methylation level of each studied CpG site and normalized gene expression

\begin{tabular}{lcrrr}
\hline & \multicolumn{4}{c}{ Methylation level } \\
Normalized gene expression & Pos.1 & Pos.2 & Pos.3 & Pos.4 \\
\hline Correlation coefficient $_{P \text {-values }}{ }^{\text {a }}$ & -0.329 & -0.282 & -0.288 & -0.304 \\
\hline P-var & $0.029^{*}$ & 0.062 & $0.045^{*}$ & 0.058 \\
\hline
\end{tabular}

a $P$-value calculated using the Pearson correlation analysis.

${ }^{*} P<0.05$.

promoter were associated with shorter GA. However, in our study, we did not find any association between DNA methylation and GA.

In order to demonstrate the functional role of promoter methylation on HSD11B2 gene expression, we analyzed HSD11B2 expression. Consistent with the above negative correlation between site-specific methylation and measures of fetal growth, inverse association was found between methylation levels of the first and the third CpG sites and HSD11B2 expression. These results might suggest that small differences in DNA methylation could drive changes in gene expression. Although few papers discussed about this issue, we did find two papers supporting our results. One animal study showed that $1.6 \%$ decrease (from 6.1 to $4.5 \%$ ) in DNA methylation of Ppar $\alpha$ explained up to $43 \%$ of the variance in Ppara gene expression. ${ }^{29}$ In a human study, small decrease (1.2 or $2.6 \%$ ) in MEST methylation was found to be associated with a 2.09-fold change in MEST expression. ${ }^{30}$

The fact that elevated methylation levels of the first and the third CpG sites were associated with reduced HSD11B2 gene expression in placenta, together with the fact that positions of the first and the third CpG sites were both predicted transcription factor ADR1 (a Zn-finger transcriptional regulator)-binding sites, suggest that promoter methylation might suppress HSD11B2 expression by preventing the binding of transcription factor ADR1 to promoter. The epigenetic regulation of HSD11B2 gene promoter by methylation highlights, therefore, a potential new mechanism whereby HSD11B2 exerts its role in the pathogenesis of IUGR.

The genesis of the higher placental HSD11B2 promoter methylation observed in some IUGR newborns is open to speculation. This study is an example of the role of promoter methylation in the regulation of HSD11B2 gene expression in the pathogenesis of IUGR, with a clear relationship between methylation level of placental HSD11B2 promoter and measures of fetal growth. Considering that epigenetic changes are potentially reversible, ${ }^{31}$ the present results may have both etiopathogenetic and therapeutic implications.

In summary, our findings associated placental HSD11B2 promoter methylation with measures of fetal growth, demonstrating that placental HSD11B2 promoter methylation alterations might have an important role in the development of IUGR. However, there are two limitations in this study. First, we do not know how promoter DNA methylation affects HSD11B2 gene expression in placentas. Second, we could not determine whether there were any other epigenetic mechanisms to regulate HSD11B2 expression. This study is only a pilot case-control study, and further mechanistic studies are needed to confirm our findings.

\section{CONFLICT OF INTEREST}

The authors declare no conflict of interest.

\section{ACKNOWLEDGEMENTS}

This work was financially supported by the Natural Science Foundation of China (Grant. 81072263 to YZ) and Shanghai Natural Science Foundation (Grant 10ZR1402000 to YZ). We thank Dr Yang Cao of Karolinska Institutet for critical comments on the manuscript.

1 Wollmann HA: Intrauterine growth restriction: definition and etiology. Horm Res 1998; 49(Suppl 2): 1-6.

2 Alexander GR, Kogan M, Bader D, Carlo W, Allen M, Mor J: US birth weight/gestational age-specific neonatal mortality: 1995-1997 rates for whites, hispanics, and blacks. Pediatrics 2003; 111: e61-e66.

3 Baschat AA: Fetal responses to placental insufficiency: an update. BJOG 2004; 111 : 1031-1041.

4 Cetin I, Alvino G: Intrauterine growth restriction: implications for placental metabolism and transport. A review. Placenta 2009; 30(Suppl A): S77-S82.

5 Lackman F, Capewell V, Richardson B, daSilva O, Gagnon R: The risks of spontaneous preterm delivery and perinatal mortality in relation to size at birth according to fetal versus neonatal growth standards. Am J Obstet Gynecol 2001; 184: 946-953.

6 Barker DJ: The long-term outcome of retarded fetal growth. Clin Obstet Gynecol 1997; 40: 853-863.

7 Benediktsson R, Lindsay RS, Noble J, Seckl JR, Edwards CR: Glucocorticoid exposure in utero: new model for adult hypertension. Lancet 1993; 341: 339-341.

8 Reinisch JM, Simon NG, Karow WG, Gandelman R: Prenatal exposure to prednisone in humans and animals retards intrauterine growth. Science 1978; 202: 436-438.

9 Phillips ID, Simonetta G, Owens JA, Robinson JS, Clarke IJ, McMillen IC: Placental restriction alters the functional development of the pituitary-adrenal axis in the sheep fetus during late gestation. Pediatr Res 1996; 40: 861-866.

10 Economides DL, Nicolaides KH, Campbell S: Metabolic and endocrine findings in appropriate and small for gestational age fetuses. J Perinat Med 1991; 19: 97-105.

11 Parker CR Jr, Buchina ES, Barefoot TK: Abnormal adrenal steroidogenesis in growthretarded newborn infants. Pediatr Res 1994; 35: 633-636.

12 Stewart PM, Murry BA, Mason JI: Type 211 beta-hydroxysteroid dehydrogenase in human fetal tissues. J Clin Endocrinol Metab 1994; 78: 1529-1532.

13 Stewart PM, Rogerson FM, Mason JI: Type 211 beta-hydroxysteroid dehydrogenase messenger ribonucleic acid and activity in human placenta and fetal membranes: its relationship to birth weight and putative role in fetal adrenal steroidogenesis. J Clin Endocrinol Metab 1995; 80: 885-890.

14 Sun K, Yang K, Challis JR: Differential regulation of 11 beta-hydroxysteroid dehydrogenase type 1 and 2 by nitric oxide in cultured human placental trophoblast and chorionic cell preparation. Endocrinology 1997; 138: 4912-4920.

15 Rogerson FM, Kayes KM, White PC: Variation in placental type 2 11betahydroxysteroid dehydrogenase activity is not related to birth weight or placental weight. Mol Cell Endocrinol 1997; 128: 103-109.

16 Bro-Rasmussen F, Buus O, Trolle D: Ratio cortisone/cortisol in mother and infant at birth. Acta Endocrinol 1962; 40: 579-583.

17 Murphy VE, Zakar T, Smith R, Giles WB, Gibson PG, Clifton VL: Reduced 11betahydroxysteroid dehydrogenase type 2 activity is associated with decreased birth weight centile in pregnancies complicated by asthma. J Clin Endocrinol Metab 2002; 87: 1660-1668.

18 Dy J, Guan H, Sampath-Kumar R, Richardson BS, Yang K: Placental 11 betahydroxysteroid dehydrogenase type 2 is reduced in pregnancies complicated with idiopathic intrauterine growth restriction: evidence that this is associated with an attenuated ratio of cortisone to cortisol in the umbilical artery. Placenta 2008; 29: 193-200. 
19 McTernan CL, Draper N, Nicholson H et al: Reduced placental 11 beta-hydroxysteroid dehydrogenase type 2 mRNA levels in human pregnancies complicated by intrauterine growth restriction: an analysis of possible mechanisms. J Clin Endocrinol Metab 2001; 86: 4979-4983.

20 Struwe E, Berzl GM, Schild RL et al: Simultaneously reduced gene expression of cortisol-activating and cortisol-inactivating enzymes in placentas of small-for-gestational-age neonates. Am J Obstet Gynecol 2007; 197: 43 e41-e46.

21 Shams M, Kilby MD, Somerset DA et al: 11Beta-hydroxysteroid dehydrogenase type 2 in human pregnancy and reduced expression in intrauterine growth restriction. Hum Reprod 1998; 13: 799-804.

22 White PC: 11beta-hydroxysteroid dehydrogenase and its role in the syndrome of apparent mineralocorticoid excess. Am J Med Sci 2001; 322: 308-315.

23 Alikhani-Koopaei R, Fouladkou F, Frey FJ, Frey BM: Epigenetic regulation of 11 beta-hydroxysteroid dehydrogenase type 2 expression. J Clin Invest 2004; 114: 1146-1157.

24 Ronco AM, Llaguno E, Epunan MJ, Llanos MN: Effect of cadmium on cortisol production and 11 beta-hydroxysteroid dehydrogenase 2 expression by cultured human choriocarcinoma cells (JEG-3). Toxicol In Vitro 2010; 24: 1532-1537.
25 Marsit CJ, Maccani MA, Padbury JF, Lester BM: Placental 11-beta hydroxysteroid dehydrogenase methylation is associated with newborn growth and a measure of neurobehavioral outcome. PLoS One 2012; 7: e33794.

26 Murthi P, Fitzpatrick E, Borg AJ, Donath S, Brennecke SP, Kalionis B: GAPDH, 18S rRNA and YWHAZ are suitable endogenous reference genes for relative gene expression studies in placental tissues from human idiopathic fetal growth restriction. Placenta 2008; 29: 798-801.

27 Maccani MA, Marsit CJ: Epigenetics in the placenta. Am J Reprod Immunol 2009; 62 78-89.

28 Bjornsson HT, Fallin MD, Feinberg AP: An integrated epigenetic and genetic approach to common human disease. Trends Genet 2004; 20: 350-358.

29 Lillycrop KA, Phillips ES, Torrens C, Hanson MA, Jackson AA, Burdge GC: Feeding pregnant rats a protein-restricted diet persistently alters the methylation of specific cytosines in the hepatic PPAR alpha promoter of the offspring. Br J Nutr 2008; 100: 278-282.

30 Katari S, Turan N, Bibikova M et al: DNA methylation and gene expression differences in children conceived in vitro or in vivo. Hum Mol Genet 2009; 18: 3769-3778.

31 Li LC, Carroll PR, Dahiya R: Epigenetic changes in prostate cancer: implication for diagnosis and treatment. J Natl Cancer Inst Jan, 19: 2005; 97: 103-115.

Supplementary Information accompanies this paper on European Journal of Human Genetics website (http://www.nature.com/ejhg) 